\title{
Photoaversion in retinitis pigmentosa
}

\author{
ATUL A GAWANDE, ${ }^{1}$ WILliaM J DONOVAN, ${ }^{* 1}$ ARTHUR P GinsBURG ${ }^{2}$, \\ AND MICHAEL F MARMOR ${ }^{1}$
}

From the ${ }^{1}$ Department of Ophthalmology, Stanford University Medical Center, Stanford, California, and ${ }^{2}$ Vistech Consultants, Inc., Dayton, Ohio, USA

SUMMARY Photoaversion, or light-induced interference with visual comfort and performance, has been a recognised but poorly documented symptom in retinitis pigmentosa (RP). We found that a majority of our RP patients complained of photoaversion even in the absence of significant cataract. RP patients had reduced contrast sensitivity relative to normal people, but the decrement in their visual performance as a result of glare or photostress was only slight. RP patients had raised short-term adaptation and increment threshold levels, but their rate of short-term or photopic adaptation was normal. Photoaversion in RP may result because a small interference with contrast sensitivity or adaptation can place patients in a range of functional disability, or it may derive from a combination of minor aberrations.

The most prominent symptoms of retinitis pigmentosa (RP) are progressive night blindness and field loss, though central vision may also be reduced. Many patients complain of difficulty in functioning in bright light (noted anecdotally by Leber in 1916), but to our knowledge there has been no documentation of the frequency, characteristics, or physiology of such symptoms.

This report represents a preliminary attempt to characterise photoaversion in RP, which we define as symptomatic interference with visual performance due to exposure to bright light. RP patients were surveyed to discover the frequency and nature of complaints, and presented with a variety of psychophysical tests to define and quantify the symptom of 'photoaversion'.

\section{Material and methods}

A total of 20 photoaversive RP patients (11 male, 9 female) performed psychophysical tests (though no subject performed all tests). The age range was $11-68$ (average 34); visual acuity ranged from 20/20 to $20 / 70$. RP was documented by history, fundus examination, ring scotoma, and electroretinography; no patients had more than a trace of posterior

\footnotetext{
*Present address: Polaroid Corporation, Vision Research Laboratory, 750 Main Street, 3E, Cambridge, Massachusetts, USA. Correspondence to Michael F Marmor, MD, Department of Ophthalmology, Stanford University Medical Center, Stanford, CA 94305, USA.
}

subcapsular opacity. The normal controls were 16 subjects (aged 16-63, average 33) with no ocular pathology, no visual complaints, and $20 / 20$ or better acuity.

To survey for symptoms we contacted personally all our RP patients whose records (within 10 years) indicated $20 / 200$ or better acuity and basically clear media, and who could be reached within a two-week study period. A total of 22 reported functional reading ability and no cataract to their knowledge; seven were in the group undergoing experimental studies. We also surveyed 19 normal people of similar ages.

CONTRAST SENSITIVITY AND GLARE TESTS Contrast sensitivity at distance was measured monocularly, in the presence and absence of glare, with Vistech charts (Vistech Consultants, Inc.). These consist of three large posters with sine-wave gratings of varying spatial frequency and contrast whose orientation may be vertical or tilted. ${ }^{2}$ Illumination was as in the manufacturer's specifications. The chart was viewed through a circular $22 \mathrm{~W}$ fluorescent bulb (GTE Sylvania), 6 inches $(15 \mathrm{~cm})$ from the face, which served as a source of glare.

Glare sensitivity was also evaluated with the Miller-Nadler Glaretester, a tabletop viewer that presents a 20/200 Snellen-equivalent black Landolt ring $^{3}$ surrounded by a circular field of variable darkness within a $6850 \mathrm{~cd} / \mathrm{m}^{2}$ glare field. Subjects were positioned $33 \mathrm{~cm}$ from the screen, and asked to 
report the ring's orientation as a function of contrast with its surround. For a subgroup of subjects the results were compared with those with the glare field masked by cardboard.

Further glare and photostress studies were performed with the Vistech Multivision Contrast Tester (Vistech Consultants, Inc.). This apparatus provides variable illumination and glare (central or peripheral) with a set of small Vistech contrast sensitivity targets and Snellen acuity letters viewed through a binocular eyepiece. To measure macular photostress, subjects were adapted to a background illumination of $18.8 \mathrm{~cd} / \mathrm{m}^{2}$ for 60 seconds and Snellen acuity measured; subjects then fixated on a 5820 $\mathrm{cd} / \mathrm{m}^{2}$ central light source for 15 seconds, and the time was noted to recover within 1 line above original acuity. To evaluate peripheral glare, the intensity of peripheral illumination was raised from $1.7 \mathrm{~cd} / \mathrm{m}^{2}$ to $240 \mathrm{~cd} / \mathrm{m}^{2}$ for 60 seconds, and the time noted to 'discomfort' from bright light, we began with a background illumination of $19 \mathrm{~cd} / \mathrm{m}^{2}$ and increased glare illumination at a steady rate. The subjects were asked to indicate "when the light reaches a level that makes you feel like squinting'. This test was performed monocularly and binocularly, and with peripheral and central glare; for each condition the average of three trials was used.

DARK ADAPTATION TESTS

We studied the early time course of adaptation by an established technique ${ }^{4}$ for measuring threshold within a fraction of a second before or after shutting off an adapting background light. A Maxwellian view recover within 1 line of original acuity. To estimate

optical system presented a $2 \cdot 5^{\circ}, 20$ millisecond, red test flash within an $8.5^{\circ}, 5.5 \mathrm{log}$ troland, yellow background. The intensity of the test flash was varied with a neutral density wedge. An electric shutter shut off the background at $T=0.8$ second, and test flashes were presented between $T=0.0$ and 1.70 seconds. The subject was asked to signal when the test flash was detected. Visual threshold was defined as the intensity at which the target was perceived $50 \%$ of the time.

Intermediate rates of dark adaptation were measured with a Goldmann/Weekers Adaptometer. Subjects viewed binocularly the variable intensity light source behind a ground glass diffuser. Target intensity was continuously and alternately increased or decreased until the subject indicated the light was just visible or invisible. Subjects were preadapted at low photopic levels $\left(68.5 \mathrm{~cd} / \mathrm{m}^{2}\right)$ for 2 minutes, and then a bright background light $\left(1370 \mathrm{~cd} / \mathrm{m}^{2}\right)$ was turned on for 3-5 minutes. Lighting was then returned to the original background level.

\section{Results}

\section{PHOTOAVERSION AS A SYMPTOM}

Twenty-two RP patients without cataracts and 19 normal subjects were asked the series of questions shown in Fig. 1. The great majority of RP patients indicated they were sensitive to light and had difficulty adjusting from outdoor to indoor illumination. Few normal people had trouble in the sun or difficulty with adaptation for more than $\mathbf{3 0}$ seconds, though they were nearly as likely as RP patients to be bothered by oncoming headlights at night. Almost all

\section{Photoaversion survey results}

WOULD YOU DESCRIBE YOURSELF AS SENSITIVE TO LIGHT?

DO YOU HAVE TROUBLE SEEING ON A BRIGHT, SUNNY AFTERNOON?

DO YOU HAVE TROUBLE SEEING WHEN YOU GO INDOORS FROM OUTDOORS?

FOR MORE THAN 30 SECONDS?

DO HEADLIGHTS GIVE YOU TROUBLE WHEN RIDING IN A CAR AT NIGHT?

Fig. 1 Answers from the survey of RP and normal subjects.

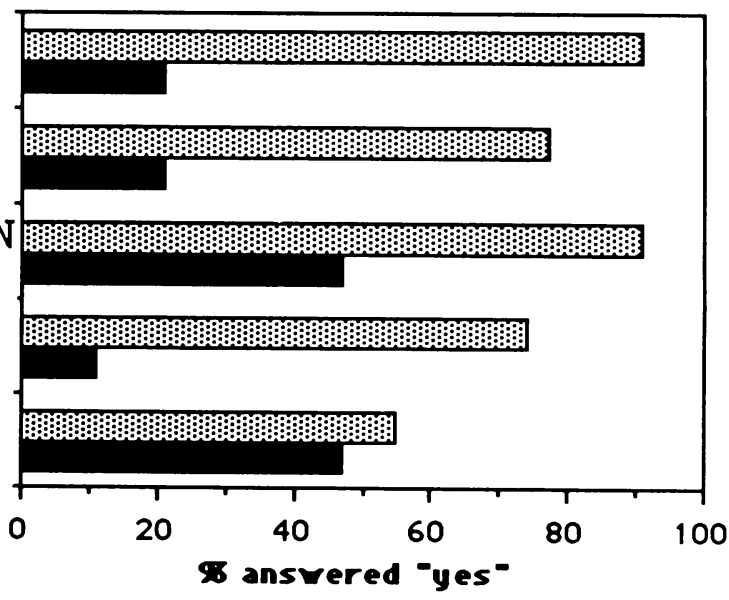


GLARE EFFECT ON CONTRAST SENSITIMTY
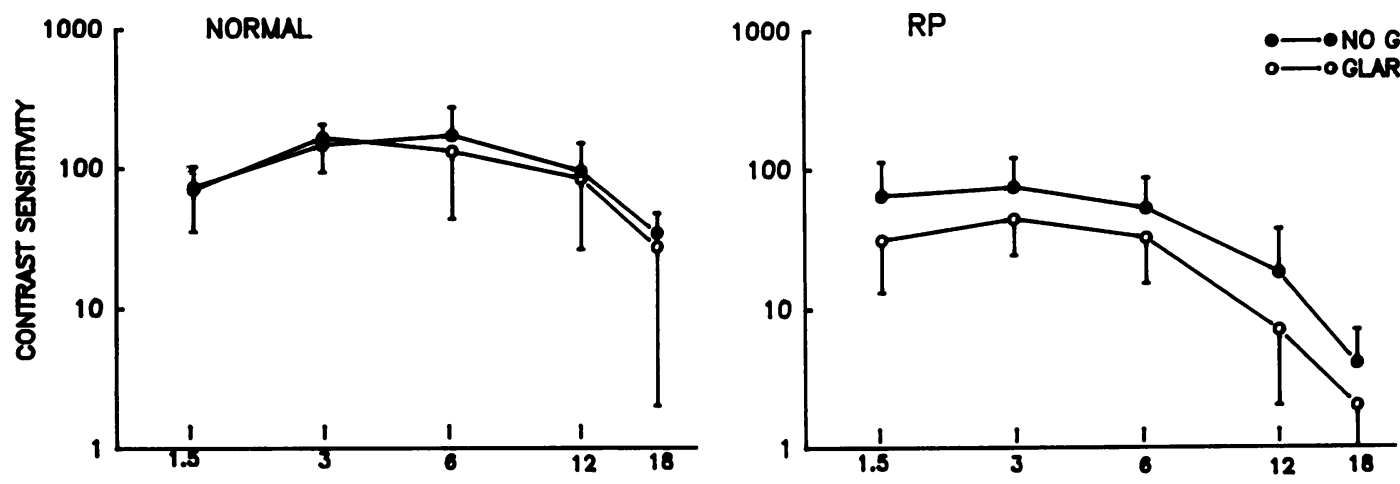

SPATLL FREQUENCY (CYCLES PER DEGREE)

Fig. 2 Contrast sensitivity data, with and without glare, for RP and normal subjects. Error bars are \pm 1 standard deviation.

(17 of 20) of the light sensitive RP subjects cited bright sun as one of the worst situations for daytime vision, with overcast or shadows less frequently cited. There was no clear consensus, however, as to whether the trouble in sunlight lasted just a few minutes or for the entire time of exposure. Only three RP patients did not wear an aid against bright light (cap, sunglasses, or a visor). The photoaversive RP patients most often complained of light as irritation, pain, or a cause of tearing; the four photosensitive normal persons noted headache or squinting.

\section{CONTRAST SENSITIVITY AND GLARE}

SENSITIVITY

The contrast sensitivity of seven RP patients and seven normal controls was tested at 10 feet $(3 \mathrm{~m})$ with Vistech posters while looking through a circular fluorescent bulb as a source of peripheral glare. Fig. 2 shows contrast sensitivity (plotted against spatial frequency) with the light on and off. RP subjects showed lower contrast sensitivity than normal people under either condition, and a roughly $0.1 \mathrm{log}$ unit greater decrement in contrast sensitivity in the presence of glare. Further to evaluate glare effects we tested nine RP and six normal subjects using the Miller-Nadler glaretester. Normal people had little difficulty with the test (only one missed one target), and the RP patients on average missed only the two most subtle targets in the presence of glare, corresponding (according to manufacturer's data) to a $5 \%$ glare disability. With the peripheral glare source masked off, a subgroup of six RP and four normal subjects recognised all of the targets.

\section{DISCOMFORT AND PHOTOSTRESS}

The results of central photostress and peripheral bright light testing of nine normal and four RP subjects are presented in Fig. 3. The scattergrams show the time for recovery of vision to 1 line above normal acuity. The RP patients generally had longer recovery times; after peripheral light exposure all the normal persons recovered visual function immediately, whereas only one of the four RP subjects had no period of delay. The scattergrams in Fig. 4 show the intensity of binocular illumination, presented either centrally or peripherally, at which subjects perceived discomfort. The discomfort levels of normals versus RP patients were not categorically different, and some RP patients were even more tolerant of bright light than the controls (despite the general complaint of photoaversion). Results from monocular testing were similar.

\section{DARK ADAPTATION IN PHOTOSENSITIVE SUBJECTS}

Data on the first 1-2 seconds of dark adaptation from five RP patients and seven normal subjects are presented in Fig. 5. RP subjects had higher thresholds than normals both before and after turning off the adapting light; however, the rate of early dark adaptation differed very little, if at all. We also tested (for three RP subjects and two normals) the speed of adaptation between levels of photopic background illumination roughly $2 \log$ units apart (Fig. 6). RP patients had higher baseline thresholds at either level of illumination than normal people, but the recovery of sensitivity on lowering the background intensity was almost immediate for both groups.

\section{Discussion}

Clinicians are aware that many RP patients complain bitterly of visual impairment or of discomfort in bright light, but we could find no reports on the 


\section{RECOVERY FROM PHOTOSTRESS}

$\Delta(95)$

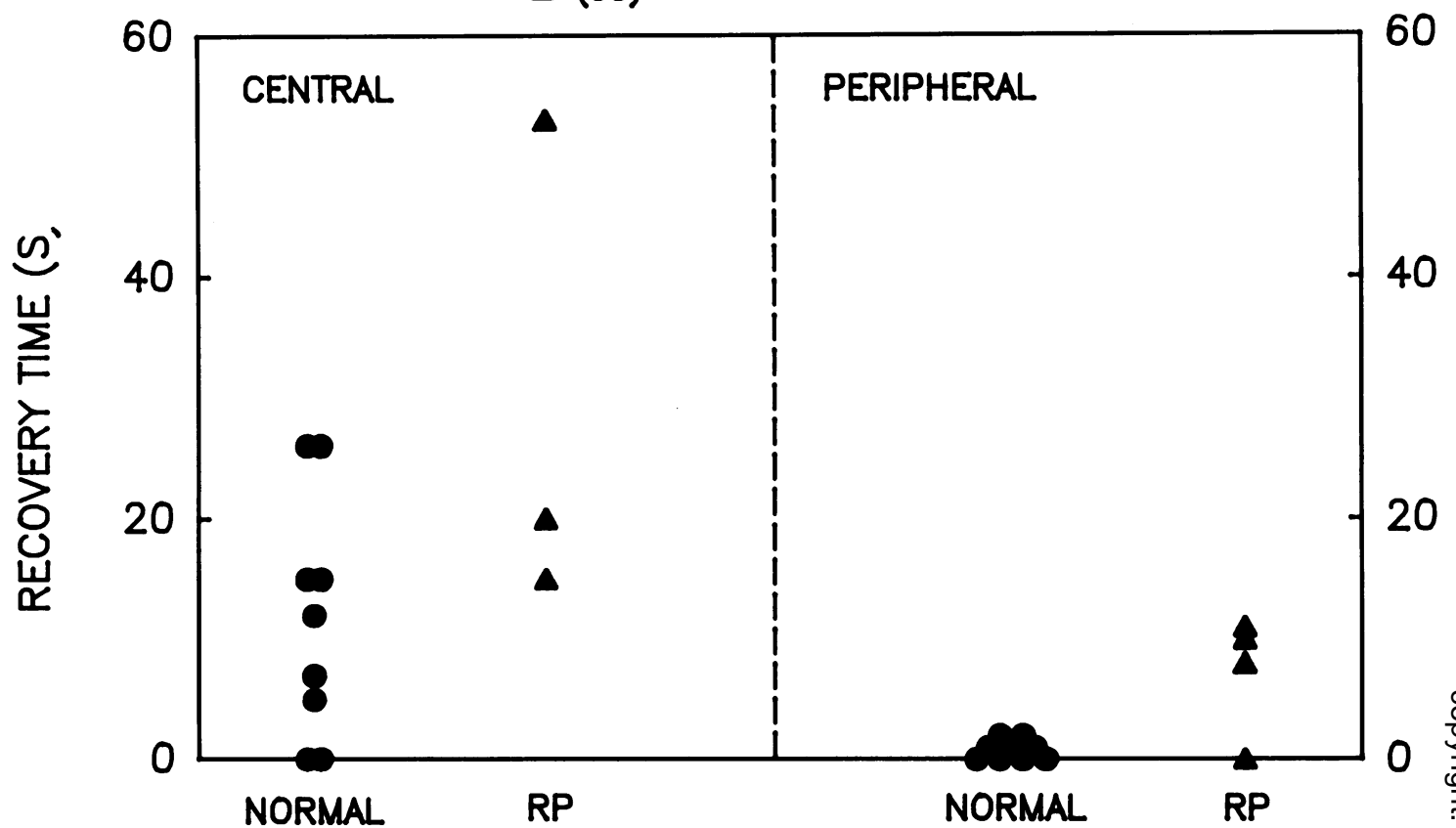

Fig. 3 Times for recovery from central photostress and peripheral light exposure for RP and normal subjects.

frequency or severity of this symptom or its pathophysiology (in the absence of a scattering source such as cataract). This report represents a preliminary attempt at resolving these issues. The number of patients studied was small, but our purpose was to seek major differences between RP patients and normal persons and study as many conditions as possible, rather than to evaluate any specific test exhaustively.

Our survey confirms the clinical impression that

\section{SUBJECTIVE DISCOMFORT TEST}
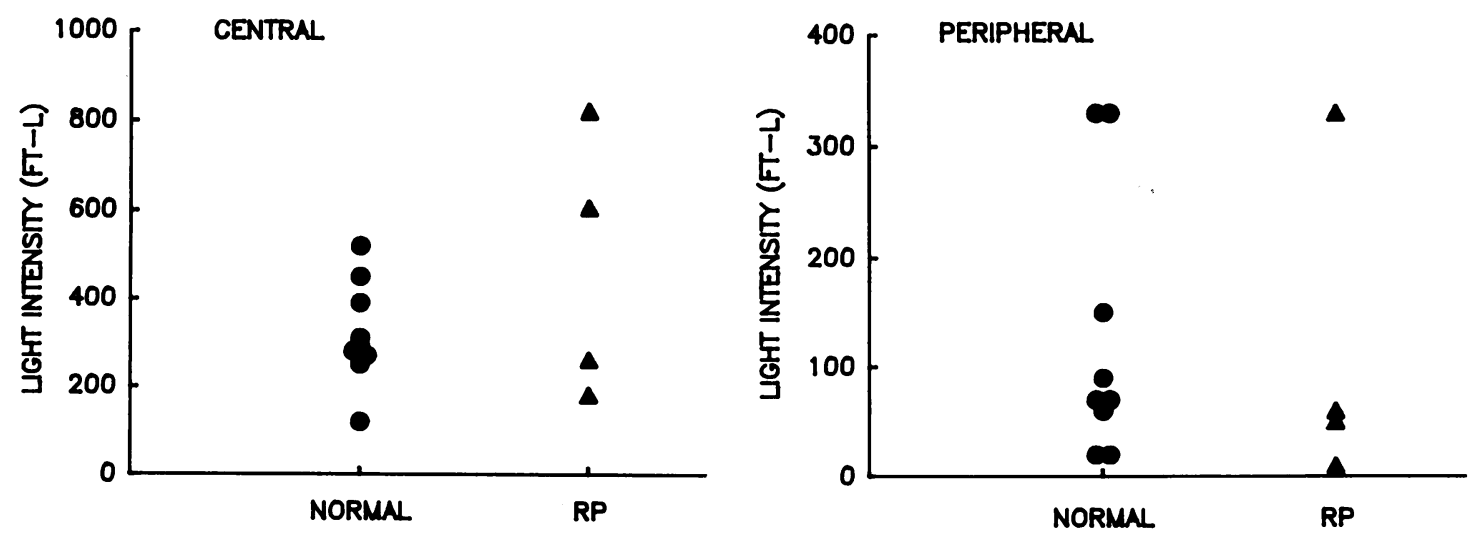

Fig. 4 Light intensities of central and peripheral.glare sources that caused subjective discomfort in RP and normal subjects. (SI conversion: foot-lambert $\times 3 \cdot 426=$ candelas per square metre.) 
EARLY DARK ADAPTATION

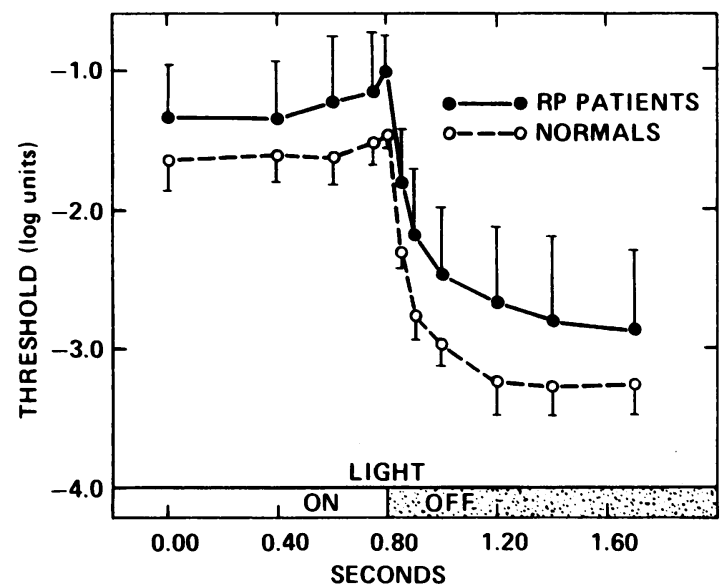

Fig. 5 Early dark adaptation data for RP and normal subjects. Error bars are \pm 1 standard deviation. photoaversion is a significant complaint in RP independent of symptoms from cataract. We have used the term 'photoaversion', since 'light sensitivity' is somewhat ambiguous (sensitivity refers to both thresholds and discomfort) and 'photophobia' is used for conditions that produce pain such as iritis. We asked patients about 'sensitivity to light', but the meaning is unambiguous in this colloquial context. Nearly all the 22 RP patients surveyed considered themselves to be light-sensitive, had difficulty in functioning in bright sun, and had difficulty recovering sensitivity after such exposure. Our psychophysical results show that it is not so easy to find quantitative confirmation or definition of these subjective symptoms.

Our study of visual recovery from photostress showed that RP patients require a longer time to recover visual acuity following a bright stress (either peripheral or central) than normal persons. However, we could not detect any difference between

\section{PHOTOPIC ADAPTATION}

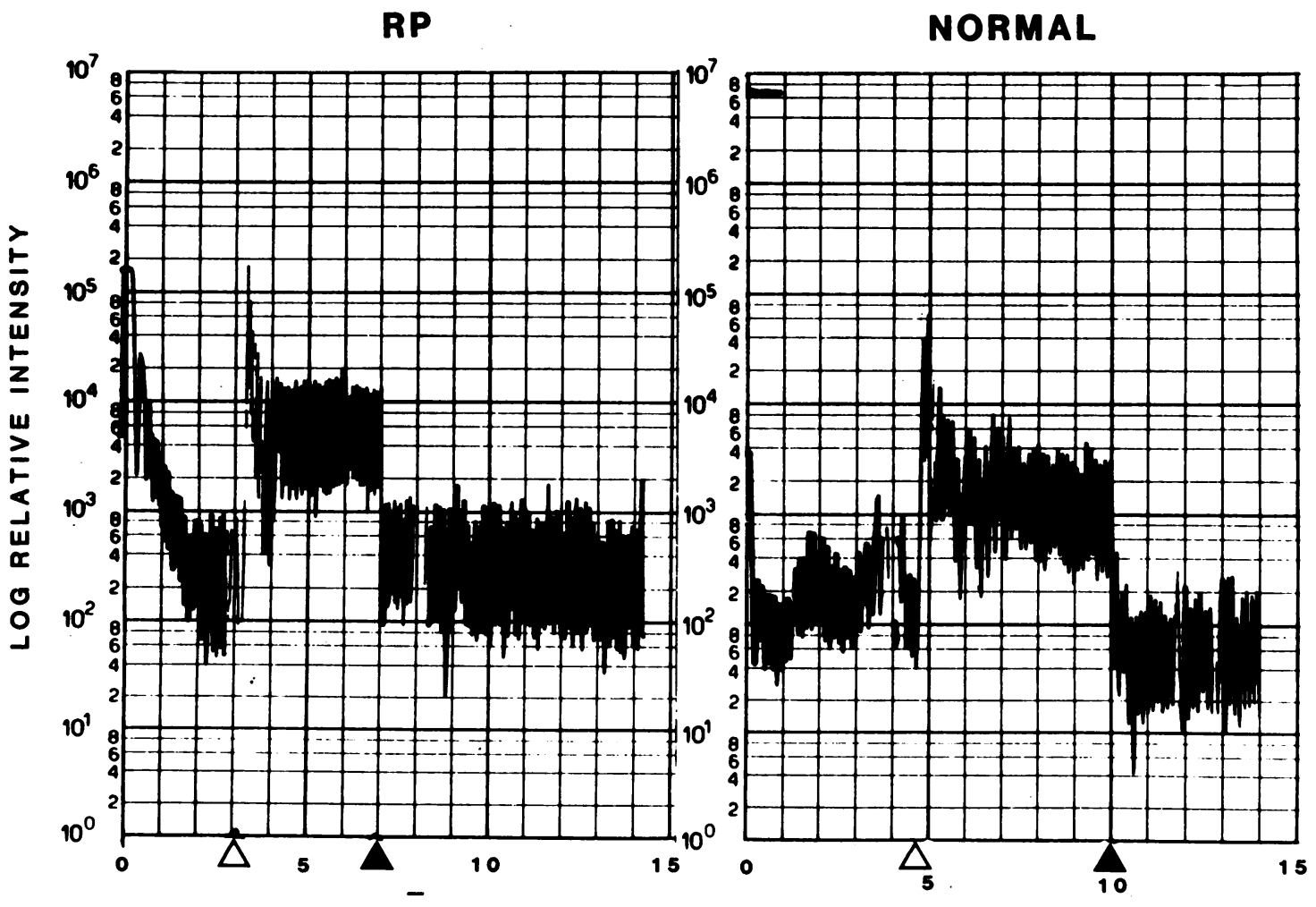

TIME (minutes)

Fig. 6 Representative tracings of adaptation between two levels of photopic illumination for a normal and RP subject (20 $\mathrm{ft}-\mathrm{L}\left(68.5 \mathrm{~cd} / \mathrm{m}^{2}\right)$ at start and finish; $400 \mathrm{ft}-\mathrm{L}\left(1370 \mathrm{~cd} / \mathrm{m}^{2}\right)$ between the arrows). 
patients and normals in the rate at which dark adaptation began. The common complaint of difficulty coming indoors may be explained by the fact that RP patients require a greater degree of adaptation before their vision finally (if ever) reaches a functional level, even though the actual rate at which photopic dark adaptation proceeds is not unusual.

The functional difficulties which RP patients describe in bright light are harder to explain. Contrast sensitivity was reduced by bright light somewhat more in RP subjects than in normal people, but this difference seems unlikely to account by itself for the symptoms of photoaversion. Furthermore, our subjective discomfort test did not indicate that patients were more sensitive to bright light than normal people despite the subjective complaints. Possibly the symptoms derive from the fact that baseline contrast sensitivity is reduced in $R P,{ }^{,-7}$ so that even a minimal further reduction due to bright light may move the patient into a range of functional disability. In other words the problem may be less one of supersensitivity to light than one of limited capacity to suffer a small light-induced decrement of function that would normally be tolerated.

Photoaversion in RP is probably not a simple consequence of photoreceptor saturation or photochemical responsiveness, since subjective discomfort levels and adaptation rates were grossly normal. The symptoms cannot be attributed to cataract, since our subjects lacked this complication-though cataract may add to the difficulties experienced by RP patients. It is possible that our studies missed relevant levels of light intensity or wavelengths in outdoor illumination which we could not duplicate in our indoor experiments. It is also quite possible that photoaversion does not, as a symptom, derive from a single physiological source, but is in fact a composite of a number of causes including glare, photostress, low discomfort threshold, altered increment threshold, and poor baseline contrast sensitivity.

Dr Ginsburg is chairman and director of research and development of Vistech Consultants, Inc., which manufactures the Vistech Contrast Sensitivity Charts and the Vistech Multivision Contrast Tester used in some parts of this project. None of the other authors have any proprietary interest in the equipment used.

This work was supported in part by the National Retinitis Pigmentosa Foundation, Retinitis Pigmentosa International and Northern California Society to Prevent Blindness, Inc.

\section{References}

1 Leber Th. Die Kranzheiten der Netzhaut. In: Graefe-SamischHess Handbuch der Gesamten Augenheilkunde. Leipzig: Englemann, 1916: 7 (2): chap. 10: 1092-4.

2 Ginsburg A. A new contrast sensitivity vision test chart. Am J Optom Physiol Opt 1984; 61: 403-7.

3 LeClaire J, Nadler MP, Weiss S, Miller D. A new glare tester for clinical testing. Arch Ophthalmol 1982; 100: 153-8.

4 Baker HD, Donovan WJ. Early dark adaptation, the receptor potential and lateral effects on the retina. Vision Res 1982; 22: 645-51.

5 Wolkstein M, Atkin A, Bodis-Wollner I. Contrast sensitivity in retinal disease. Ophthalmology 1980; 87: 1140-9.

6 Marmor MF. Contrast sensitivity and retinal disease. Ann Ophthalmol 1981; 13: 1069-71.

7 Lindberg CR, Fishman GA, Anderson RH, Vasquez V. Contrast sensitivity in retinitis pigmentosa. Br J Ophthalmol 1981; 65: 855-8.

Accepted for publication 1 September 1988. 